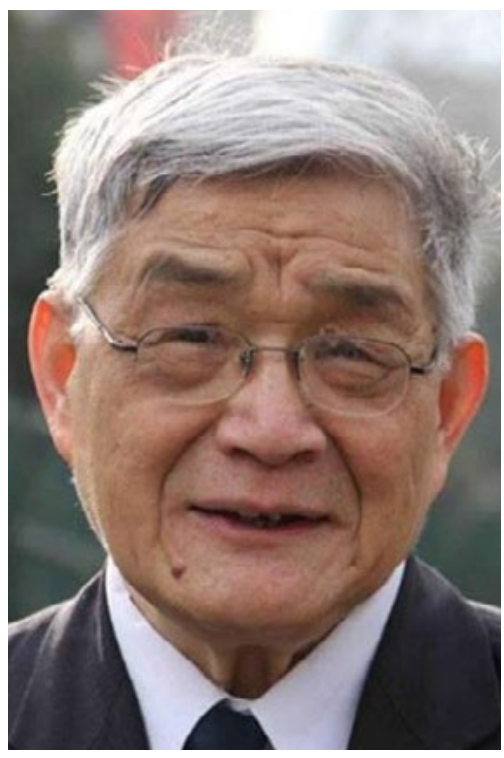

\title{
Entrevista
}

Xu Shicheng,

latinoamericanista de

la Academia de Ciencias

Sociales de China (CASS)

\section{ASIA Y AMÉRICA LATINA HAN DE UNIRSE Y SOLIDARIZARSE, COMO COMPAÑEROS DEL MISMO BARCO}

Por Qingjun Wu' y Jorge Moraga²

DOI: https://doi.org/10.51188/rrts.num24.482

El profesor Xu es una verdadera leyenda. No sólo es uno de los académicos chinos que más conoce América Latina, sobre cuyos procesos ha escrito más de 20 libros, sino que también es reconocido por la intensidad de sus vivencias. Por nombrar algunas, cortó caña en los primeros años de la revolución en Cuba, donde conoció al Che Guevara, sembró arrozales en granjas del Ejército durante la revolución cultural en China y fue observador de procesos políticos en la Venezuela de Hugo Chávez.

En los inicios de la RPC, fue uno de los precursores de los estudios latinoamericanos. Luego fue nombrado vice-director del Instituto de América Latina (IAL), cargo que ejerció entre 1985-1995. Actualmente es miembro honorario de la Academia de Ciencias Sociales de China (CASS), la principal institución sobre esas disciplinas, e investigador-profesor titular del mismo IAL. Con 78 años de edad, sin duda uno de los principales latinoamericanistas chinos, respondió las preguntas del equipo editorial de Rumbos en entrevista realizada el 19 de noviembre de 2020.

1 Doctor (c) en Relaciones chino-latinoamericanas, Jinan University, China. Director de la Oficina para América Latina del Centro Latinoamericano de la Universidad de Jinan, China.

Email: victorwu1105@gmail.com

2 Doctor en Antropología Social. Profesor investigador de la Universidad Central de Chile. Facultad de Derecho y Humanidades-Vicerrectoría Académica. Lord Cochrane 417, Santiago CP: 8330507, Chile. Email: jorge.moraga@ucentral.cl 


\section{-¿Podría contarnos en qué consiste su trabajo académico? ¿Cuáles han sido sus principales temas de interés?}

-En la actualidad me dedico a estudiar sobre los sistemas políticos, la actual situación política, social y económica y la diplomacia de los países de América Latina y El Caribe (ALC), las relaciones entre China y ALC, las relaciones entre ALC y los EE.UU. y las relaciones triangulares entre China, ALC y los EE.UU., entre otros temas.

He publicado en los últimos años los siguientes libros: Historia Contemporánea de América Latina, Historia de las Relaciones Internacionales de América Latina, Confrontación: Fidel Castro vs. Ios Presidentes de los EE.UU., Civilización de América Latina, El proceso de la modernización y los cambios del modelo político y económico de México, El Hegemonismo Imperial y América Latina, Las reformas políticas y económicas de México y el cambio de su modelo, Estudios sobre el sistema político de los países latinoamericanos, Política Latinoamericana, Biografía de Fidel Castro, Los Altibajos del PRI, Las Corrientes de Pensamientos de América Latina Contemporánea, Biografía de Hugo Chávez, El Socialismo en América Latina, La actualización del modelo de Cuba y la emergencia de la izquierda en América Latina, La colorida cultura contemporánea de América Latina, Estudios sobre las izquierdas y las corrientes ideológicas de la teoría socialista de América Latina.

\section{HACE FALTA MAYOR COORDINACIÓN E INTERCAMBIO ACADÉMICO}

\section{-Según su opinión ¿Cuáles son los principales desafíos para los estudios sobre Asia y América Latina en Ciencias Sociales y Humanidades?}

-Pienso que los principales desafíos para los estudios sobre Asia y América Latina en Ciencias Sociales y Humanidades son que no hay una coordinación entre los estudiosos sobre Asia y América Latina, tanto en China como en ALC. Hay muy pocos trabajos sobre los vínculos, tanto históricos como actuales, entre Asia y ALC. Hace falta una mayor coordinación entre los investigadores de China, Japón, Corea del Sur, India con los investigadores de Chile, México, Brasil, Argentina y otros países de ALC, a través de visitas mutuas, simposios, intercambios de informaciones, etc.

\section{-En China en particular ¿en qué situación se encuentran los estudios de $A L$ y cuáles son las principales áreas de interés y estudio?}

-Los estudios sobre ALC en China empezaron desde 1949, después de la fundación de la República Popular de China. Se creó en 1961 el primer centro de estudios sobre ALC: el Instituto de América Latina, anexo a la Academia China, poco después del triunfo de la Revolución Cubana. En las décadas de 50, 60 y 70, las principales áreas de interés y estudio son el movimiento democrático y nacional de ALC, la lucha contra el colonialismo, el imperialismo y el hegemonismo de los países de ALC, los modelos de desarrollo de ALC, la teoría de CEPAL, etc. Y gracias a la Reforma y Apertura al Exterior, desde finales de 1978, los estudios sobre ALC en China entraron en una nueva etapa. Se crearon en China la Sociedad de Estudios sobre las Literaturas Hispanas y la Sociedad de Estudios sobre la Historia de ALC en 1979, y la Asociación China de Estudios Latinoamericanos en 1984. Aumentó 
el número de centros de estudios sobre ALC situados principalmente en Beijing, Tianjin, Shanghai y Wuhan. $Y$ al entrar en el siglo XXI, a medida que se desarrollan con rapidez las relaciones entre China y ALC, se vienen creando aún más centros de estudios sobre ALC en toda China. Hasta 2019, en China se totaliza 58 institutos o centros de estudios sobre ALC, la mayoría se sitúa en las universidades. Se amplía las áreas de interés y estudio, abarcando los principales problemas tanto de la historia, como de la actualidad, y abarcando también los principales países y subregiones de ALC. Se han publicado unos centenares de libros o traducciones de las obras y trabajos de los eruditos latinoamericanos. Aumentan los intercambios académicos con los principales centros de investigación y universidades de los países de ALC. Hay también un creciente intercambio de estudiantes y profesores entre China y ALC.

Sin embargo, todavía hay bastantes deficiencias en los estudios sobre ALC en China.

\section{EN CHINA HAY UN CONOCIMIENTO SUPERFICIAL SOBRE AMÉRICA LATINA}

\section{- Mirando el futuro ¿qué temas considera fundamentales para estimular los vínculos entre las academias de ambos continentes?}

-A mi modo de ver, las academias de ambos continentes podrían trabajar conjuntamente los siguientes temas:

1 La emigración asiática en ALC: Los primeros emigrantes asiáticos en ALC; La emigración asiática en Brasil, Cuba, Perú, Panamá, Chile y Argentina; en Surinan, Guyana, Barbados y otros países o islas caribeñas.

2 Los vínculos económicos y comerciales entre Asia y ALC: comercio, inversión, empresas asiáticas en ALC, etc.

3 Las estratégicas hacia Asia-Pacífico de Chile, Colombia, Perú, Ecuador, México y la Alianza Pacífica.

4 Estudios sobre Forum for East Asia and Latin America Cooperation.

\section{-¿Cuáles son las percepciones comunes de la gente de su país sobre América Latina?}

-Los conocimientos de la gente común de China sobre ALC viene aumentando gradualmente. En términos generales, la gente ve con buenos ojos el rápido desarrollo de las relaciones bilaterales entre China y ALC, y está bastante satisfecha de la creciente cooperación económica, del aumento del intercambio cultural y deportivo. A la gente le gustan los productos agropecuarios y alimenticios de ALC como soja, carne, pescado, lácteos, vino, café y frutas. La gente común sabe de Fidel Castro, Hugo Chávez, Salvador Allende, Pinochet, Lula, Bolsonaro, Luis Echeverría, Perón, etc.; conoce a García Márquez, Pablo Neruda, Vargas Llosa, Jorge Luis Borges, José Martí, Simón Bolívar, San Martín, etc.; conoce Diego Maradona, Pelé, 
Ronaldo y otros famosos futbolistas; les gusta ver tango, salsa, samba y escuchar la música latina.

Sin embargo, todavía son pobres y superficiales los conocimientos de la gente común sobre ALC.

Debido al desarrollo de las TIC y nuevas plataformas como Youtube, las culturas asiáticas llegan y se conocen cada vez más en América Latina. En su opinión ¿qué efectos están generando estos cambios en la compresión bilateral entre los pueblos de ambos continentes?

En los últimos años, debido al desarrollo de las TIC y nuevas plataformas, la cultura china llega y se conoce cada vez más en América Latina. En términos generales, aumenta el porcentaje de la gente común de ALC que tiene una percepción positiva sobre China, la mayoría de los latinoamericanos ven en China como socios de cooperación. Gracias a los esfuerzos de los institutos de Confucio, creados en la última década en los países de ALC, se profundiza poco a poco la mutua compresión y se mejora la imagen de China en ALC. Sin embargo, todavía falta mucho. En comparación con la música, las telenovelas y las películas de los EE. UU. y los países europeos, no hay muchos aficionados en ALC a la música, las telenovelas y las películas de China. Y por eso hace falta aumentar los intercambios culturales entre China y ALC.

La humanidad enfrenta distintos desafíos como las violaciones de derechos humanos, migraciones, cambio climático, la cuarta revolución industrial, por dar algunos ejemplos, sin hablar de la pandemia actual ¿Cómo Asia y América Latina, cruzando las fronteras y el Pacífico, podrán trabajar juntos frente a estos desafíos comunes en esta era de gran transición?

Para enfrentar distintos desafíos comunes hace falta una mayor cooperación y coordinación entre China, los países de Asia y de ALC en las distintas organizaciones concernientes de la ONU, en otros organismos e instituciones internacionales, y también una mayor cooperación y coordinación bilaterales entre China y los países de ALC. ¿Podrá la recién creada Asociación Económica Integral Regional (RCEP) coordinarse y cooperar con CPTPP y Alianza del Pacífico para enfrenta distintos desafíos? 


\section{COVID 19: LAS PRÁCTICAS INTIMIDATORIAS Y LAS CORRIENTES DESGLOBALIZADORAS EXACERBAN LA INCERTIDUMBRE MUNDIAL}

La pandemia es otra instancia que invita a pensar el orden global centrado hasta ahora en Europa y EE.UU. ¿Qué rol podrán jugar Asia y América Latina, que hasta ahora de cierta manera han estado más marginados, en el nuevo orden global y cómo afectará la convivencia de la humanidad a futuro?

Actualmente, la humanidad se halla en un período histórico especial. La pandemia de COVID-19 ha acelerado la evolución de grandes cambios mundiales nunca vistos en cien años, a saber, la profunda recesión de la economía mundial, las embestidas a las cadenas globales industriales y de suministro, los crecientes déficits de gobernanza, confianza, desarrollo y paz, etc. El repunte del unilateralismo y el proteccionismo, las prácticas intimidatorias así como las corrientes desglobalizadoras han exacerbado los riesgos y la incertidumbre en la economía mundial.

Una respuesta colaborativa entre Asia y América Latina a los retos jugará un rol importante para la recuperación de la economía mundial y para establecer un nuevo orden global. Esta pandemia nos recuerda una vez más que nuestro mundo es una comunidad de futuro compartido indivisible en la que ninguna nación puede salvarse sola y los intereses de todos los países están estrechamente vinculados. Tanto la victoria definitiva de la lucha global contra COVID-19, como la recuperación de la economía mundial requieren la unidad y la colaboración de Asia y América Latina y de toda la comunidad internacional. Los países de Asia y América Latina han de unirse y solidarizarse, para combatir conjuntamente las tempestades como compañeros del mismo barco, hacer valer el espíritu de socio, reforzar la comunicación y la coordinación de las políticas, ahondar en toda línea la cooperación en la lucha contra COVID-19 y apostar por una economía mundial abierta, a fin de vencer el virus lo antes posible, y lograr un crecimiento vigoroso, sostenible, equilibrado e incluyente de la economía mundial.

Asia y América Latina son nuestro hogar, y por lo tanto, salvaguardar la paz y seguridad y fomentar el desarrollo y prosperidad de Asia y América Latina corresponden a los intereses de todos nosotros. Asia y América Latina están destinados a profundizar la cooperación económica, porque esto concuerda con la aspiración de nuestros pueblos, y por eso esta cooperación seguirá contando con una fuerte vitalidad. 